\title{
The distinctive gastric fluid proteome in gastric cancer reveals a multi-biomarker diagnostic profile
} Oi Lian Kon*1, Tai-Tung Yip ${ }^{2}$, Meng Fatt $\mathrm{Ho}^{1}$, Weng Hoong Chan ${ }^{3}$, Wai Keong Wong ${ }^{3}$, Soo Yong Tan ${ }^{4}$, Wai Har Ng${ }^{1}$, Siok Yuen Kam¹, Alvin KH Eng1,2, Patrick $\mathrm{Ho}^{2}$, Rosa Viner ${ }^{2}$, Hock Soo Ong ${ }^{3}$ and $\mathrm{M}$ Priyanthi Kumarasinghe ${ }^{4}$

\begin{abstract}
Address: ${ }^{1}$ Division of Medical Sciences, Humphrey Oei Institute of Cancer Research, National Cancer Centre, Singapore, Republic of Singapore, ${ }^{2}$ Ciphergen Biosystems Inc., Fremont, USA, ${ }^{3}$ Department of General Surgery, Singapore General Hospital, Singapore, Republic of Singapore and ${ }^{4}$ Department of Pathology, Singapore General Hospital, Singapore, Republic of Singapore
\end{abstract}

Email: Oi Lian Kon* - dmskol@nccs.com.sg; Tai-Tung Yip - tyip27@gmail.com; Meng Fatt Ho - dmshmf@nccs.com.sg; Weng Hoong Chan - gsucwh@sgh.com.sg; Wai Keong Wong - gsuwwk@sgh.com.sg; Soo Yong Tan - drtansy@gmail.com; Wai Har Ng - nmsnwh@nccs.com.sg; Siok Yuen Kam - nmsksy@nccs.com.sg; Alvin KH Eng - doctor2906@yahoo.com.sg; Patrick Ho - pho@ciphergen.com; Rosa Viner - rviner@ciphergen.com; Hock Soo Ong - gzzohs@sgh.com.sg; M

Priyanthi Kumarasinghe - pkumarasinghe@yahoo.co.uk

* Corresponding author

Published: 25 October 2008

BMC Medical Genomics 2008, I:54 doi:10.1 186/1755-8794-I-54

This article is available from: http://www.biomedcentral.com/I755-8794/I/54

(c) 2008 Kon et al; licensee BioMed Central Ltd.

This is an Open Access article distributed under the terms of the Creative Commons Attribution License (http://creativecommons.org/licenses/by/2.0), which permits unrestricted use, distribution, and reproduction in any medium, provided the original work is properly cited.

\begin{abstract}
Background: Overall gastric cancer survival remains poor mainly because there are no reliable methods for identifying highly curable early stage disease. Multi-protein profiling of gastric fluids, obtained from the anatomic site of pathology, could reveal diagnostic proteomic fingerprints.

Methods: Protein profiles were generated from gastric fluid samples of 19 gastric cancer and 36 benign gastritides patients undergoing elective, clinically-indicated gastroscopy using surface-enhanced laser desorption/ ionization time-of-flight mass spectrometry on multiple ProteinChip arrays. Proteomic features were compared by significance analysis of microarray algorithm and two-way hierarchical clustering. A second blinded sample set (24 gastric cancers and 29 clinically benign gastritides) was used for validation.

Results: By significance analysyis of microarray, 60 proteomic features were up-regulated and 46 were downregulated in gastric cancer samples $(p<0.01)$. Multimarker clustering showed two distinctive proteomic profiles independent of age and ethnicity. Eighteen of 19 cancer samples clustered together (sensitivity $95 \%$ ) while $27 / 36$ of non-cancer samples clustered in a second group. Nine non-cancer samples that clustered with cancer samples included 5 pre-malignant lesions ( $\mathrm{I}$ adenomatous polyp and 4 intestinal metaplasia). Validation using a second sample set showed the sensitivity and specificity to be $88 \%$ and $93 \%$, respectively. Positive predictive value of the combined data was 0.80 . Selected peptide sequencing identified pepsinogen $C$ and pepsin $A$ activation peptide as significantly down-regulated and alpha-defensin as significantly up-regulated.
\end{abstract}

Conclusion: This simple and reproducible multimarker proteomic assay could supplement clinical gastroscopic evaluation of symptomatic patients to enhance diagnostic accuracy for gastric cancer and pre-malignant lesions. 


\section{Background}

Unlike other common cancers, the prognosis for most gastric cancer patients is poor and has improved little over the past several decades. Five-year survival rates for gastric cancer are considerably lower than all major cancers except cancers of the liver, pancreas and esophagus [1]. Given that early stage gastric cancer has a much better prognosis (5-year survival approximately 90\%) than advanced gastric cancer (5-year survival 3-10\%) [2,3], global mortality from gastric cancer ought to decrease substantially by measures that result in downstaging of tumors at the time of initial diagnosis.

Although gastroscopy is the gold standard for gastric cancer diagnosis, its accuracy is not as high as it is for benign gastric diseases such as peptic ulcers, especially in geographic regions of low to intermediate gastric cancer prevalence. The percentage of missed cancer diagnosis, reported as $4.6 \%, 14 \%$ and even 33\% [4-6], is not insignificant. Even in Japan, the false negative rate was reported to be $19 \%$ [7]. These data are consistent with the positive predictive value of only $0.4-0.7$ for endoscopic diagnosis of gastric cancer in different centers [8-10]. Although the proportion of missed diagnoses appears small, the absolute number of patients denied the benefit of diagnosis at a curable stage is not negligible. Even at a modestly low false positive diagnostic rate of $5 \%$, more than 47,000 gastric cancers would have been missed in one low prevalence country alone (USA) in a single year, 2000 [11]. Endoscopic assessment frequently includes mucosal biopsies but there are no clinical standards for either the optimal number of biopsies or the anatomic regions that should be sampled. A commonly cited recommendation is to take at least seven biopsies to correctly diagnose gastric cancer [12]. In this study however, fully $17 \%$ of all lesions subsequently shown to be malignant were considered benign on endoscopy. Thus, endoscopic mucosal examination suffers from inter-observer variation, suboptimal correlation with histopathology, difficulty in detecting submucosal cancers and unimpeded visualization of all anatomic sub-regions e.g. after previous gastric surgery $[13,14]$.

Gastric fluid consists of a mixture of secreted soluble and exfoliated cellular proteins from the entire gastric mucosa - including regions that cannot be adequately assessed by fibreoptic gastroscopy. We therefore reasoned that the proteomic profile of gastric fluid, usually regarded as a waste by-product during gastroscopic examination, could usefully supplement conventional clinical evaluation by providing a 'molecular biopsy' that effectively samples the entire gastric mucosa, especially as protein detection techniques such as mass spectrometry can be highly sensitive. If performed during the course of clinically indicated gastroscopy, obtaining gastric fluid does not increase the invasiveness of the procedure. Unlike the plasma proteome, the gastric fluid proteome is likely to be less complex but enriched in disease-specific biomarkers, being generated directly at the disease site. The same biomarkers, even if present in plasma, may be diluted beyond the limits of detection and admixed with other more abundant systemic proteins that reflect concurrent pathophysiologic conditions (e.g. co-morbid diseases), rather than anatomic site-specific disease.

We have investigated a novel approach to developing biomarkers for gastric cancer by profiling soluble secreted peptides present in endoscopically aspirated gastric fluid and proteins extracted from exfoliated epithelial cells, also recovered during endoscopy by surface-enhanced laser desorption-ionization time-of-flight (SELDI TOF) mass spectrometry. Our results suggest that multiple protein biomarkers from an organ-specific source i.e. gastric fluid, generate a distinctive gastric cancer signature that merits further development as a tool for improving the diagnostic accuracy of gastroscopy and has potential for detecting early stage gastric cancer and pre-malignant lesions (intestinal metaplasia and dysplasia).

\section{Methods \\ Clinical samples}

Gastric fluids were obtained during gastroscopy of overnight fasted patients seen at the Singapore General Hospital. The study protocol was approved by the Ethics Committee of the Singapore General Hospital. and conformed to the provisions of the Declaration of Helsinki 1995. Indications for gastroscopy were solely clinical and were independent of the study. Initial analysis was performed on a training set of 19 samples from histologically proven gastric adenocarcinomas (13 intestinal type, 4 diffuse type, 1 mixed type, 1 indeterminate) [15] and 36 samples from patients with clinically benign gastric conditions. The mean age of 19 gastric cancer patients (13 male, 6 female; 17 Chinese, 2 Indian) was 68 years. Distribution by American Joint Committee on Cancer (AJCC) clinical staging was stage 0 ( 1 patient), stage I (4 patients), stage II ( 2 patients), stage III ( 2 patients) and stage IV (10 patients). The mean age of 36 patients with benign gastric conditions (19 male, 17 female; 33 Chinese, 2 Malay, 1 Indian) was 57 years. Clinical diagnoses after endoscopy of non-cancer patients were normal (9), antral gastritis (9), gastritis (6), ulcer (4), hiatal hernia (3), hyperplastic polyps (2), Barrett's esophagus (1), fundic scar (1) and adenomatous polyp (1).

The classification algorithm developed from the training set was tested by blinded analysis of a validation set consisting of another 24 histologically confirmed gastric adenocarcinomas (10 intestinal type, 7 diffuse type, 1 mixed type, 5 indeterminate, 1 neuroendocrine) and 29 clini- 
cally benign gastric samples. The mean age of these 24 gastric cancer patients (18 males, 6 females; 21 Chinese, 3 Malay) was 70 years. Distribution by AJCC clinical staging was stage I ( 5 patients), stage II (4 patients), stage III (2 patients) and stage IV (12 patients). One patient in the validation set declined further investigation and could not be staged. The mean age of 29 non-cancer patients (11 male, 18 female; 26 Chinese, 2 Indian, 1 Malay) was 47 years. Clinical diagnoses after gastroscopy of non-cancer patients were gastritis (14), fundic gland polyps (2), acute gastric ulcer (2), duodenitis (2), hiatal hernia (1) and normal (8).

None of the gastric cancer patients had received any form of cancer treatment at the time of gastroscopy.

Taking training and validation cases together, 19\% (8/43) and $29 \%(19 / 65)$ of patients with gastric cancer and benign gastric conditions, respectively, were positive for H. pylori, a difference that was not significant by Fisher's exact test $(2$-sided $p$ value $=0.4508)$.

\section{Sample collection and processing}

Gastric fluid was aspirated into a sterile container at commencement of endoscopy, assigned an anonymised code and immediately placed on ice. Blood- or bile-stained samples were rejected. Only clinically suspicious mucosal lesions were biopsied at the discretion of the endoscopist. Gastric fluids were centrifuged at $180 \mathrm{~g}$ for 6 minutes at $4^{\circ} \mathrm{C}$, from which the supernatant was centrifuged again at $16100 \mathrm{~g}$ for 30 minutes at $4^{\circ} \mathrm{C}$. Pellets from both centrifugations were combined. The high-speed supernatants were stored separately from the pellets at $-80^{\circ} \mathrm{C}$.

\section{Protein profiling}

After thawing, $10 \mu \mathrm{l}$ of each gastric fluid sample was applied to different chemical surfaces of ProteinChip arrays (Ciphergen Biosystems Inc, California, USA): (a) copper(II) Immobilized Metal Affinity Capture (IMAC3) in the presence of $100 \mu \mathrm{l}$ of $1 \mathrm{~mol} / \mathrm{L}$ urea, $1 \mathrm{~g} / \mathrm{L} \mathrm{3-[(3-}$ cholamidopropyl)dimethylammonio]-1-propanesulfonate (CHAPS), $0.3 \mathrm{~mol} / \mathrm{L} \mathrm{KCl}$, protease inhibitor cocktail (Roche Diagnostics, Mannheim, Germany), $50 \mathrm{~mol} / \mathrm{L}$ TrisHCl, pH 7.5; (b) Weak Cation Exchange (WCX2 and CM10) in the presence of $100 \mu \mathrm{l}$ of $50 \mathrm{mmol} / \mathrm{L}$ sodium acetate, $1 \mathrm{~g} / \mathrm{L}$ octyl glucopyranoside, protease inhibitor cocktail, pH 5; (c) Strong Anion Exchange (SAX2) in the presence of $100 \mu \mathrm{l}$ of $50 \mathrm{mmol} / \mathrm{L}$ TrisHCl, $1 \mathrm{~g} / \mathrm{L}$ CHAPS, protease inhibitor cocktail, $\mathrm{pH} 8$; and (d) Hydrophobic Interaction (H50) in the presence of $100 \mu \mathrm{l}$ of $5 \mathrm{~mL} / \mathrm{L}$ trifluoroacetic acid. After washing with $100 \mu \mathrm{l}$ of the same respective buffers, sinapinic acid was added to facilitate desorption and ionization. The chips were analysed by SELDI-TOF-MS (PBSII, Ciphergen Biosystems Inc). Cancers and controls were intermingled and run concurrently on the same chip and on multiple chips to minimize chipto-chip variation.

The gastric fluid pellets were resuspended in $25 \mu \mathrm{l}$ of 6 $\mathrm{mol} / \mathrm{L}$ guanidine thiocyanate, $5 \mathrm{~g} / \mathrm{L}$ octyl glucopyranoside, $0.1 \mathrm{~mol} / \mathrm{L} \mathrm{Hepes} \mathrm{pH} 7$, and 100-200 $\mu \mathrm{l}$ of $9 \mathrm{~mol} / \mathrm{L}$ urea, $2 \mathrm{~g} / \mathrm{L}$ CHAPS, $50 \mathrm{mmol} / \mathrm{L}$ TrisHCl, pH 7.5 by vortexing for 45 minutes at $4{ }^{\circ} \mathrm{C}$. After centrifugation at 20000 $\mathrm{g}$ for 5 minutes, $10 \mu \mathrm{l}$ of the extract was applied to ProteinChip arrays as described above.

A retentate map was generated in which individual proteins were displayed as separate peaks on the basis of their mass to charge ratio. Data of the proteomic spectra were analyzed by Ciphergen Express Data Manager Software with Pattern Track and two-way hierarchical clustering algorithm. Aligned peaks with signal to noise ratios above 3 were normalized by total ion current. Proteomic features were further analyzed using the significance analysis of microarrays (SAM) software from Stanford University. The package was designed to address problems specific to microarray data analysis (signal to noise ratio variance different from gene to gene, large number of data points from a small number of samples) but we found it to be applicable to proteomic data analysis as well. The algorithm of the software was described by Tusher et al. [16]. In brief it defined a metric called the relative difference for measuring the difference between two or more groups of data in place of the $p$ value. It employed a variation of the bootstrapping method and repeatedly divided a given data set (spectra containing the proteomic features in this study) randomly into two groups to calculate the relative difference for each of the permutations. The number of permutations was set to be 1000 in this study and the software computed 1000 relative difference values for each proteomic feature. The relative difference of the particular grouping of interest (observed relative difference) was compared to the average relative difference from all the permutations (expected relative difference) of each feature and the feature was judged to be up- or down-regulated according to whether its observed relative difference was greater or smaller than its expected relative difference by some threshold. The software estimated a false discovery rate (also defined in reference [16]) for each threshold value that provided an indirect means to set the cutoff. The markers identified by this method were statistically significant. The false discovery rate was set to be less than 0.05 in this study.

To validate the markers identified by SAM, a second batch of 53 blinded samples were added to the data set for hierarchical clustering using the Ciphergen Express Data Manager software. While the known samples used by SAM to select the markers were expected to perform well in the clustering, the blinded samples were included to test how 
well the markers generalize to unknown samples. The results of the clustering were simply compared against the true identity of the samples and no advanced classification method or any other software was used in the validation.

\section{Biomarker identification}

Gastric fluid proteins were fractionated by anion exchange chromatography (Q HyperD, Ciphergen Biosystems Inc.), using stepwise changes in $\mathrm{pH}$ for elution. Proteins in the $50 \mathrm{mmol} / \mathrm{L}$ TrisHCl, $1 \mathrm{~g} / \mathrm{L}$ octyl glucopyranoside, $\mathrm{pH} 8$ eluants were further purified on a cation exchange array (LWCX30) using $50 \mathrm{mmol} / \mathrm{L}$ sodium acetate, $1 \mathrm{~g} / \mathrm{L}$ octyl glucopyranoside, $\mathrm{pH} 5$ as binding and washing buffer. After addition of alpha-cyano-4-hydroxycinnamic acid energy absorbing molecules (Ciphergen Biosystems Inc.), the retained proteins were analyzed by PBSII and Q-TOF (Waters/Micromass) equipped with a ProteinChip Interface (PCI 1000, Ciphergen Biosystems Inc). Proteins were characterized by MS/MS fragmentation and identification was done by database search with Mascot (Matrix Science Ltd., London, UK).

\section{Biomarker validation}

This was performed in a third set of gastric fluid samples taken from benign gastric and gastric cancer patients. Each freshly collected sample was processed to remove solid debris and to concentrate the protein content as follows. After adding phenylmethanesulfonyl fluoride to a final concentration of $0.2 \mathrm{mM}$, the sample was centrifuged for 15 minutes at $500 \mathrm{~g}$ and $4{ }^{\circ} \mathrm{C}$. Protease inhibitors (Complete Mini ${ }^{\mathrm{TM}}$, Roche Applied Science, Indianapolis, IN, USA) were added to the supernatant followed by centrifugal membrane filtration at $2900 \mathrm{~g}$ and $15^{\circ} \mathrm{C}$ (Amicon Ultra-4 centrifugal filter device, 5000 nominal molecular weight limit; Millipore, Billerica, MA, USA) until the sample was reduced to $10-20 \%$ of its original volume. Total protein concentration was determined by the 2-D Quant Kit (Amersham Biosciences, Pisctaway, NJ, USA). Pepsinogen $C$ and alpha-defensin 1-3 concentrations were determined by enzyme-linked immunoassay (ELISA) using kits from Alpco Diagnostics (Salem, NH, USA) and Hycult biotechnology b.v. (Uden, The Netherlands), respectively. Each processed sample was assayed in duplicate for pepsinogen $\mathrm{C}$ and defensin levels using the suppliers' protocols. Samples for pepsinogen $C$ assay were pre-diluted 120-fold. Concentrations of pepsinogen C and alpha-defensin 1-3 were derived by reference to their respective standard curves and expressed as ng (pepsinogen C) or pg (defensin) per microgram of total gastric fluid protein.

\section{Helicobacter pylori}

The presence of $H$. pylori in stomach tissues was identified by visualization of spiral microorganisms in histology sec- tions and/or by immunohistochemistry. Four-micron tissue sections were de-waxed in xylene and decreasing grades of ethanol. Antigen retrieval was by heating in citrate buffer, $\mathrm{pH}$ 6.0. The primary antibody against $H$. pylori (1:50 dilution; DAKO A/S, Glostrup, Denmark) was followed by the secondary antibody polymer link (Envision Chem Mate, DAKO) and visualized using diaminobenzidine as chromogen.

\section{Results}

Multiple up- or down-regulated protein biomarkers in gastric cancer were discovered in gastric fluid. A representative proteomic map of gastric fluid is shown in Figure 1. It is a gel view of a mass spectrum showing gastric fluid proteins selectively bound to immobilized copper(II) metal ion in the molecular weight range of $1500 \mathrm{Da}$ to $6000 \mathrm{Da}$. Significant protein markers found to be downregulated in cancer gastric fluid $(p<0.01)$ are indicated by arrows.

A representative proteomic map of gastric fluid pellet extract is shown in Figure 2. Proteins were selectively bound to a cation exchange array surface. Significant protein markers found to be up- or down-regulated in gastric cancer fluid pellet $(p<0.01)$ are indicated by arrows.

Average CV (coefficient of variation; cumulative for 10-15 major gastric fluid peaks per spectrum, $\mathrm{n}=8$ ) for immobilized copper(II) ProteinChip array (IMAC3) was 12.8\%, for cation exchange array (WCX2) was $15 \%$, for anion exchange array (SAX2) was $17.3 \%$, and for hydrophobic interaction chip (H50) was $13.6 \%$. These CV values are in line with reproducibility assessment in the SELDI literature $[17,18]$.

By SAM analysis of all proteomic features (total number of features 41 800, average number per retentate map 314) in gastric fluid and pellet extract, 46 proteomic features were found to be significantly down-regulated in gastric cancer and 60 proteomic features were significantly upregulated in gastric cancer. (Data from different conditions, e.g., fluid and pellet as well as different surfaces, were simply aggregated together as distinct features for SAM. Markers reported by SAM in both pellet and supernatant fractions were manually identified and represented only once in the list after they were deemed biologically significant). Significantly down-regulated markers included 1884, 2428, 2594, 2840, 4050, 11720, 13700 $\mathrm{Da}$; significantly up-regulated markers included 1761, $1831,3372,3443,3605,5160,6780 \mathrm{Da}$. (Most of the significant markers were discovered on WCX2 and IMACcopper(II), followed by SAX2). Based on the 106 significantly different proteomic features (Additional file 1), two-way hierarchical clustering analysis (two-dimensional complete linkage) was performed. Most of the gas- 


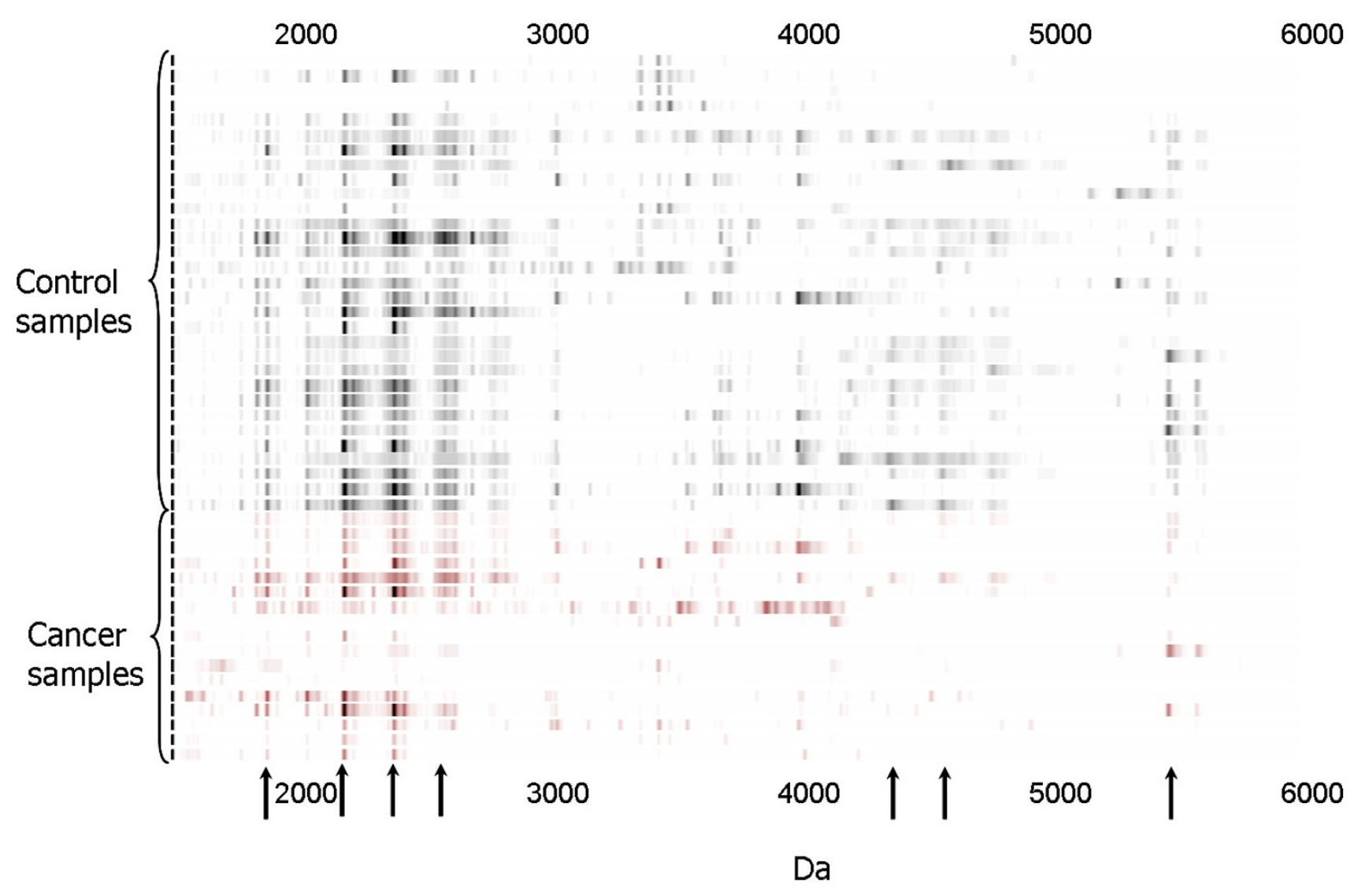

\begin{abstract}
Figure I
Expression difference map of gastric fluid on copper(II) immobilized metal affinity capture ProteinChip array (IMAC3). Arrows indicate protein biomarkers significantly different in expression level between the two groups of samples.
\end{abstract}

tric cancer cases were clustered together to form a distinctive group (Figure 3 and Additional file 2). Principal component analysis of the same data also revealed that cancer and benign samples could be well separated into two groups, with 2 false negatives (representing duplicate analysis of the same case) and 9 false positives, respectively (Figure 4). One gastric cancer fluid sample (from a case of stage I poorly differentiated gastric adenocarcinoma) clustered among non-cancer samples; all the other 4 early stage (stages 0 and I) patients correctly clustered with samples from 14 patients with stage II - IV gastric cancer, giving an overall diagnostic sensitivity of $95 \%$ (18/19 gastric cancer patients) on the training set.

Nine of 36 non-cancer samples in the training set clustered with the cancer samples (specificity 75\%). Of these, 1 had a dysplastic adenomatous polyp - a precancerous lesion [19]. Among the other 8 patients, 6 had clinically directed biopsies that revealed intestinal metaplasia in 4 patients (67\%). Eight non-cancer patients whose gastric fluid protein profiles clustered in the normal group also had clinically directed mucosal biopsies that showed intestinal metaplasia in only 2 patients (25\%). A review of 1000 consecutive gastric biopsies performed for all indications showed an overall prevalence of intestinal metaplasia in the Singapore General Hospital during the study period of $30 \%$. This contrasts with the prevalence of at least $67 \%$ of intestinal metaplasia among clinically benign cases whose proteomic profiles clustered more closely with gastric cancer cases than with other normals, consistent with intestinal metaplasia being an intermediate state in the transition of normal gastric epithelium to gastric adenocarcinoma. Accurate identification of intestinal metaplasia by endoscopy is known to be inaccurate [20]. Thus, a gastric cancer-type proteomic fingerprint is possibly a sensitive indicator for the presence of this premalignant lesion among patients clinically diagnosed as having benign gastric disorders.

Gastric cancer patients in the training set were significantly older (mean age 67.7 years) than patients with benign gastric conditions (mean age 56.6) $(p=0.0062)$. 


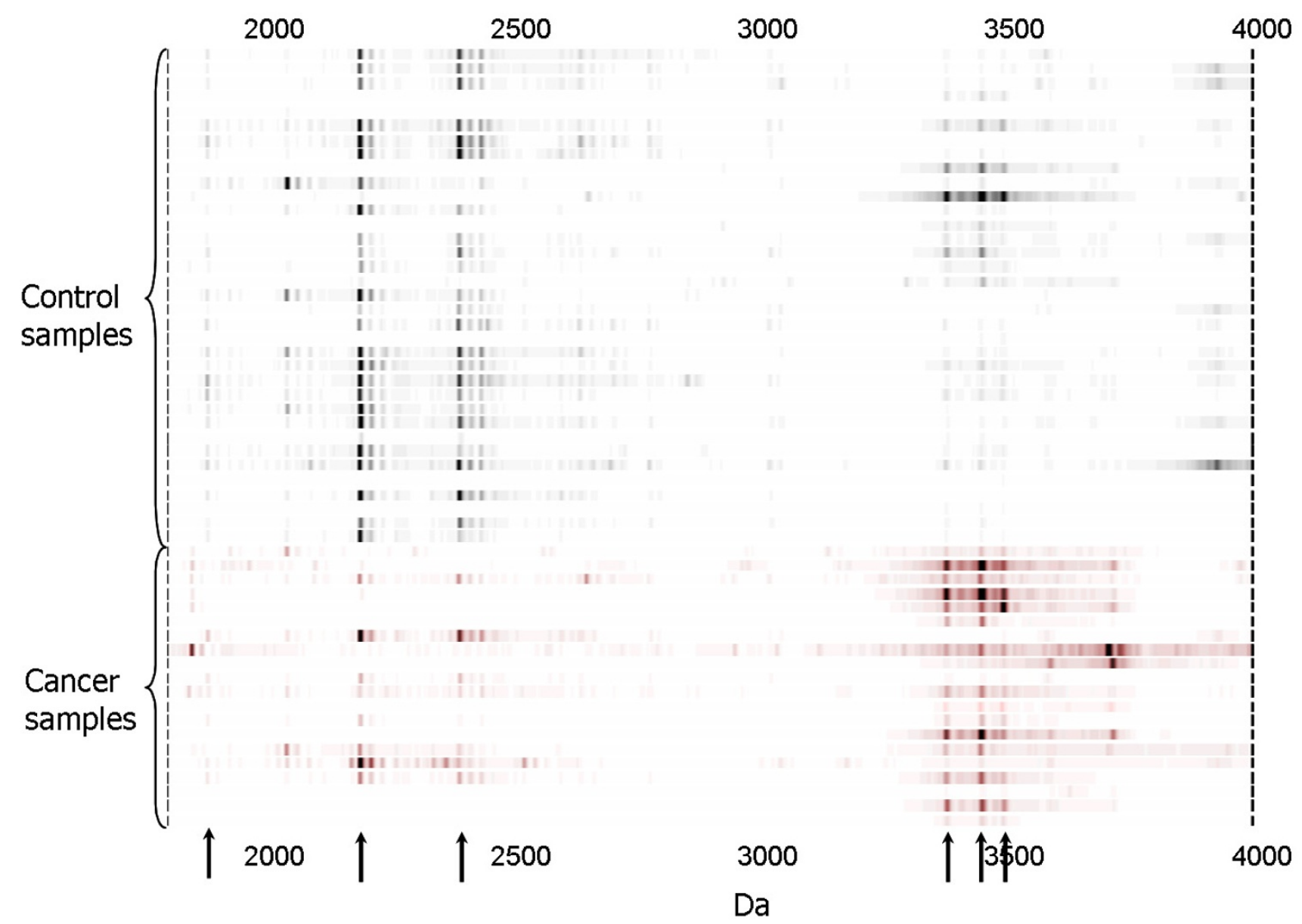

Figure 2

Expression difference map of gastric fluid pellet extract on cation exchange ProteinChip array (WCX2).

Arrows indicate protein biomarkers significantly different in expression level between the two groups of samples.

To address the possibility that protein profiles were related to age or ethnicity, we re-analyzed data of the subset of Chinese patients above 55 years of age. This resulted in $1 / 17$ cancers misclassified (the same tumor that was misclassified when all 19 cancers were analyzed; sensitivity $94 \%$ ) and $4 / 17$ controls misclassified (the same 4 controls that were among the 9 misclassified benign cases; specificity $76.5 \%$ ).

We next tested the actual performance of proteomic profiles in distinguishing cancer from benign samples in a second series of 53 blinded gastric fluid and pellet extract samples (24 gastric cancers and 29 benign gastric disorders) (Additional file 3). Twenty-one of 24 gastric cancers were correctly identified (sensitivity 88\%) and 2 of 29 benign samples were wrongly classified (specificity 93\%) (Figure 5).
Selected proteomic markers (based on significance score determined by SAM) were semi-purified on ProteinChip arrays and identified directly on spots by collisioninduced dissociation sequencing (Figure 6). Several of the significantly down-regulated markers in cancer patients shown in Figures 1 and 2, 1881.9 Da, 2041.0 Da, 2188.1 Da and 2387.3 Da, were identified to be pepsinogen $\mathrm{C}$ and pepsin A activation peptide fragments (Table 1). The up-regulated triplet markers in cancer patients shown in Figures 2, 7 and Additional file 4 were identified to be alpha defensin-1,2,3. Intensity scatter plots show highly significant differences in the mean intensities of defensin and pepsin fragment between benign control and gastric cancer fluid samples ( $p=0.003$ and 0.00002 , respectively) (Figure 8). Using ELISA specific for pepsinogen C, we confirmed significantly lower concentrations in gastric cancer fluids $(11.9 \pm 0.1 \mathrm{ng} / \mu \mathrm{g}$ total protein; mean \pm s.e.m. $\mathrm{n}=$ 6.) compared to benign samples $(21.5 \pm 1.4 \mathrm{ng} / \mu \mathrm{g}$ total 

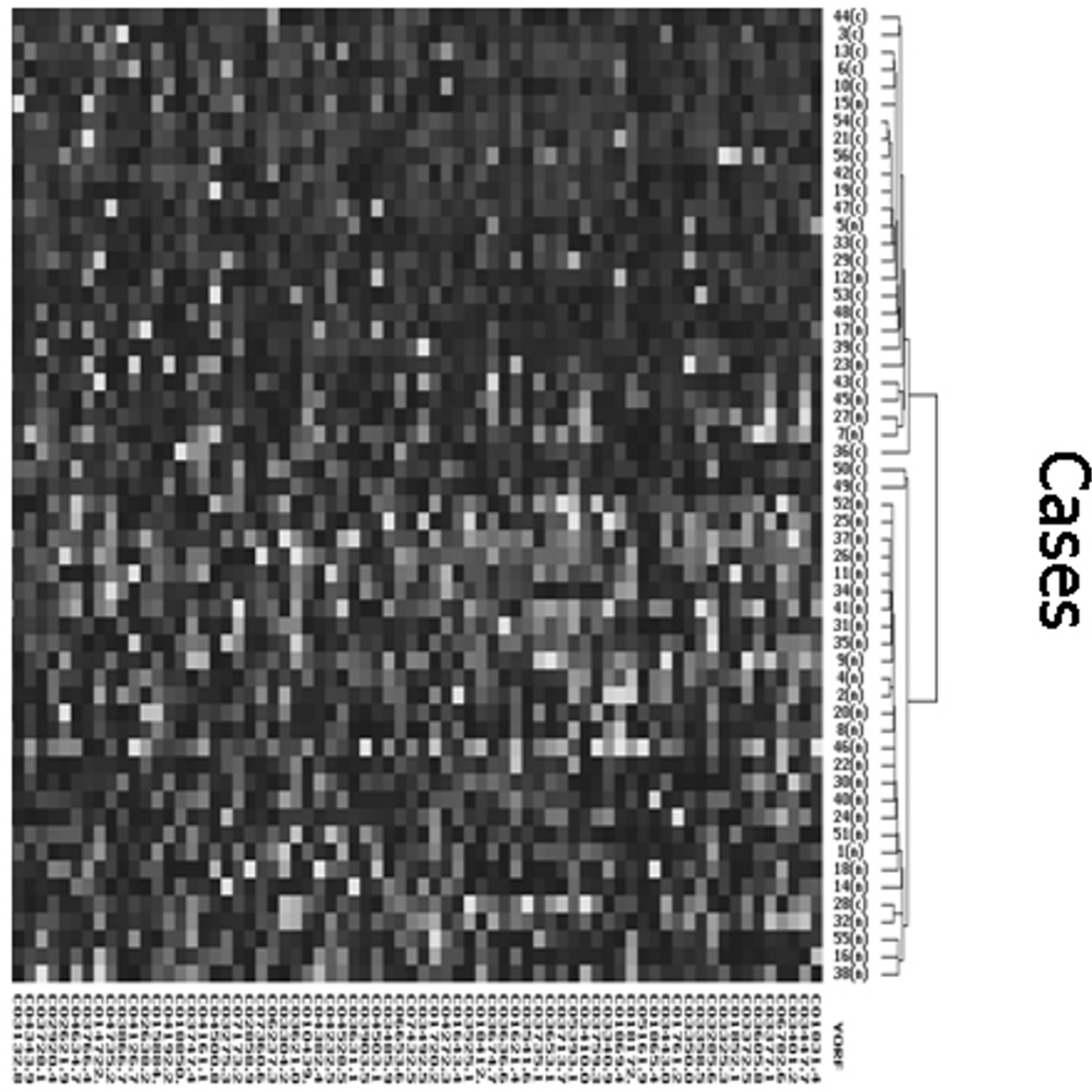

\section{Differentially expressed proteomic features}

\section{Figure 3}

Expression difference map of gastric fluid and pellet extract proteins of training set samples on four ProteinChip arrays, displayed in two-way hierarchical clustering. Significant proteomic features are displayed vertically. The intensity of the grayscale indicates the degree of relative protein level, higher or lower than the median value. Patient cases are presented horizontally; most gastric cancer patients are tightly clustered together. This figure shows the upper quartile of the full image (please see Additional file 2 for the full image).

protein. $\mathrm{n}=23)$ in a third sample set $(p=0.0126$; Student's unpaired two-tailed $t$ test). ELISA performed on the same sample set for defensin levels showed higher concentrations in gastric cancer samples $(63.4 \pm 9.2 \mathrm{pg} / \mu \mathrm{g}$ total protein; mean \pm s.e.m. $\mathrm{n}=6$ ) than in benign samples $(46.2 \mathrm{pg} / \mu \mathrm{g}$ total protein; mean \pm s.e.m. $\mathrm{n}=23)((p=$ 0.0654 ; Student's $t$ test).

\section{Discussion}

Our data suggest that the spectral profile of unfractionated gastric fluid could be a useful adjunct for cancer diagnosis and detection of early stage disease, when combined with clinical gastroscopy. Most recent attempts at identifying protein biomarkers for gastric cancer have investigated serum [21-29] and tissue [24,30-37], and have increasingly used mass spectrometry. Older reports of serological 


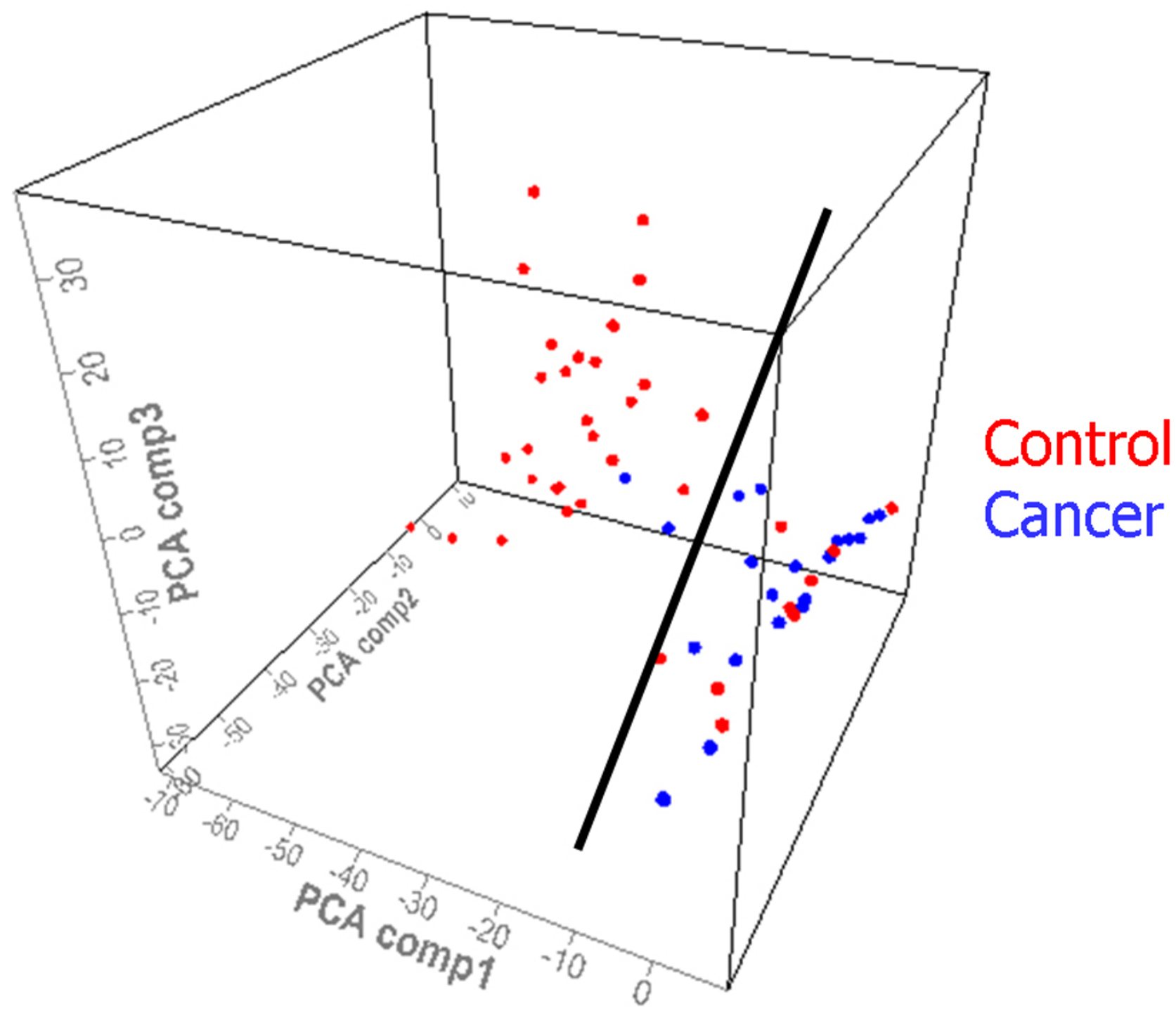

Figure 4

Principal component analysis plot of proteomic features of training set samples. A single plane (denoted by the black line) divides the samples into two groups with I false negative (shown in duplicate spots) and 9 false positives.

assays of individual known tumor markers e.g. CEA, CA 19-9, CA 72-4, CA242 and TAG-72, have generally low sensitivity $(<50 \%)$ [38-41]. Moreover, there is substantial cross-positivity of these tumor markers in non-gastric cancers e.g. raised CEA and MG7-Ag levels are common in colorectal cancer, cholangiocarcinoma, pancreatic carcinoma, and even in healthy controls $[40,23]$. Not surprisingly, such serum tumor markers have no established role in gastric cancer diagnosis and screening, although they may serve as prognostic indicators and early markers of recurrent disease following gastrectomy $[39,41,42]$.
We chose to examine proteomic profiles of gastric fluid for disease biomarkers because it seemed likely that perturbed gastric protein secretion in malignant and premalignant states, coupled with the possible presence of exfoliated cancer cells, could generate distinctive proteomic profiles. As in the search for serum biomarkers, several groups have investigated the diagnostic utility of known tumor markers in gastric juice. Neither CEA nor CA 19-9 positivity in gastric fluid has demonstrated diagnostic accuracy [43-46]. Alpha-1 antitrypsin in gastric juice has recently been reported as a gastric cancer biomarker $[47,48]$. 


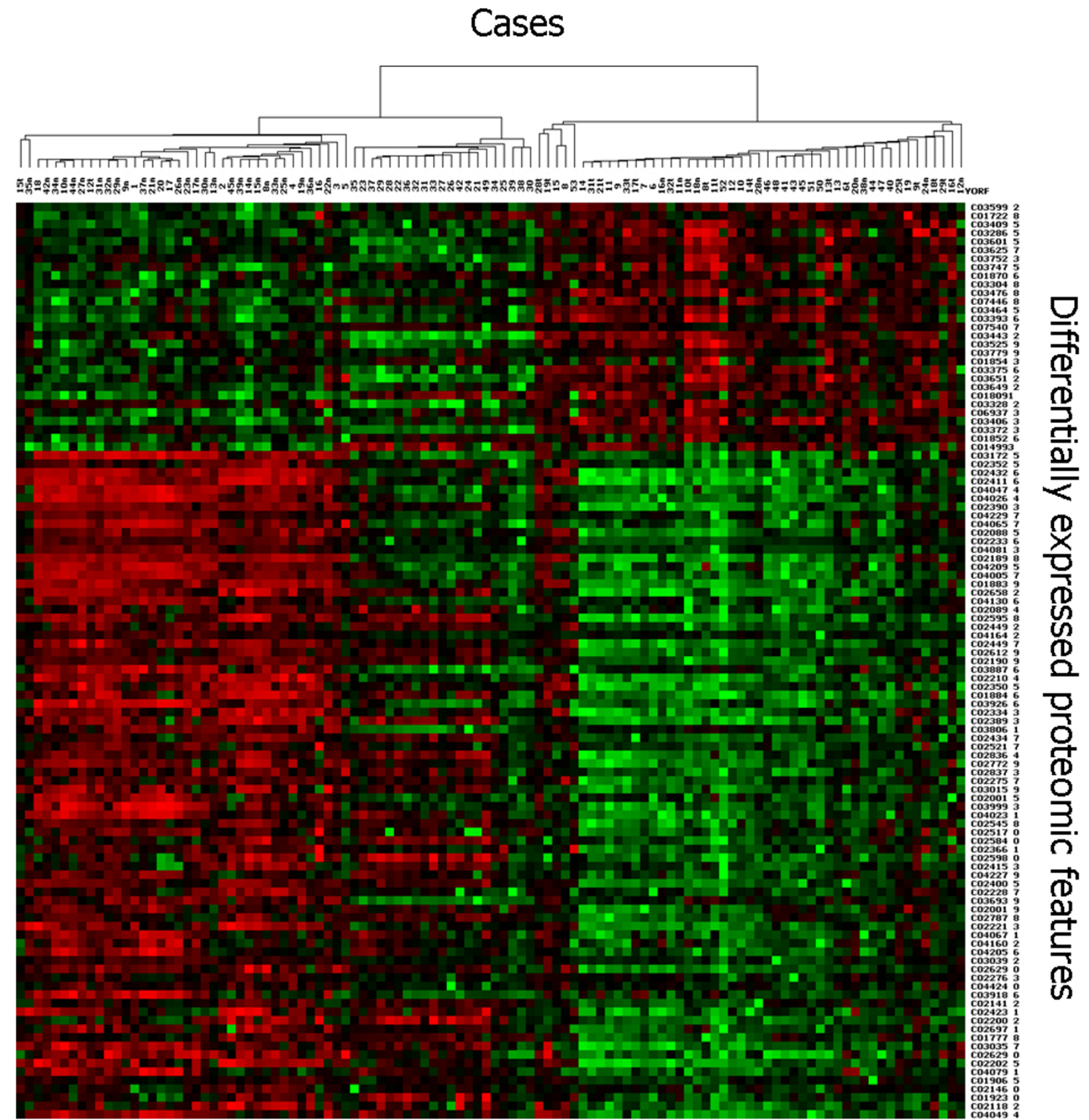

Figure 5

Expression difference map of gastric fluid and pellet extract proteins of validation set samples on four ProteinChip arrays, displayed in two-way hierarchical clustering. Significant proteomic features are displayed horizontally. The intensity of the red or green colours indicates the degree of relative protein level, higher or lower than the median value. Patient cases are presented vertically; most gastric cancer patients are tightly clustered together. 
Table I: Peptide sequences identified by MS//MS

\begin{tabular}{lllll}
\hline Peptide $\mathbf{m} / \mathbf{z}$ & Sequence & Protein Match & Mowset score & Mowse score with significant homology \\
\hline 2386.29 & FLKKHNLNPARKYFPQWKA & Pepsin A activation peptide & 35 & $>28$ \\
2187.12 & FLKKHNLNPARKYFPQW & Pepsin A activation peptide & 18 & $>26$ \\
2040.03 & LKKHNLNPARKYFPQW & Pepsin A activation peptide & 28 & $>26$ \\
1775.95 & FLKKHNLNPARKYF & Pepsin A activation peptide & 47 & $>26$ \\
1628.84 & LKKHNLNPARKYF & Pepsin A activation peptide & 40 & $>28$ \\
\hline 1880.92 & LRTHKYDPAWKYRF & Pepsinogen C activation peptide & 31 & $>22$ \\
\hline
\end{tabular}

tMowse score $=-10 \log (P)$, where $P=$ probability that the match is a random event $(P<0.05) \mathrm{m} / \mathrm{z}$, mass $/$ charge

Our approach to developing a sensitive method for gastric cancer diagnosis differed from previous studies in three ways. First, we chose a biological sample that was organspecific (i.e. endoscopically aspirated gastric fluid) rather than systemic (i.e. serum), reasoning that the molecular features would more likely be disease-specific. Second, mass spectrometry enabled us to take an unbiased discovery-based approach. Third, our data generated profiles of multiple proteomic markers that are increasingly regarded as having higher sensitivity and specificity than single tumor markers $[49,50]$. For gastric cancer, combining even 2 or 3 tumor markers achieved better diagnostic accuracy compared to a single marker alone $[38,40]$.
Protein fingerprints of gastric fluid from gastric cancer patients showed a total of 106 proteomic features that were significantly up- or down-regulated (Additional files 1 and 3). Two prominent markers were selected for identification by MS/MS. Pepsinogen A and pepsinogen C activation peptides were down-regulated in gastric fluids removed from stomachs with histologically confirmed adenocarcinomas. A study of cryostat sections of gastric cancer has also reported significant down-regulation of pepsinogen C, identified by MS/MS, in tumor tissue [51]. Reduced pepsinogen levels in blood and tissue are a wellknown consequence of multifocal chronic atrophic gastritis, a histopathological condition which increases the risk

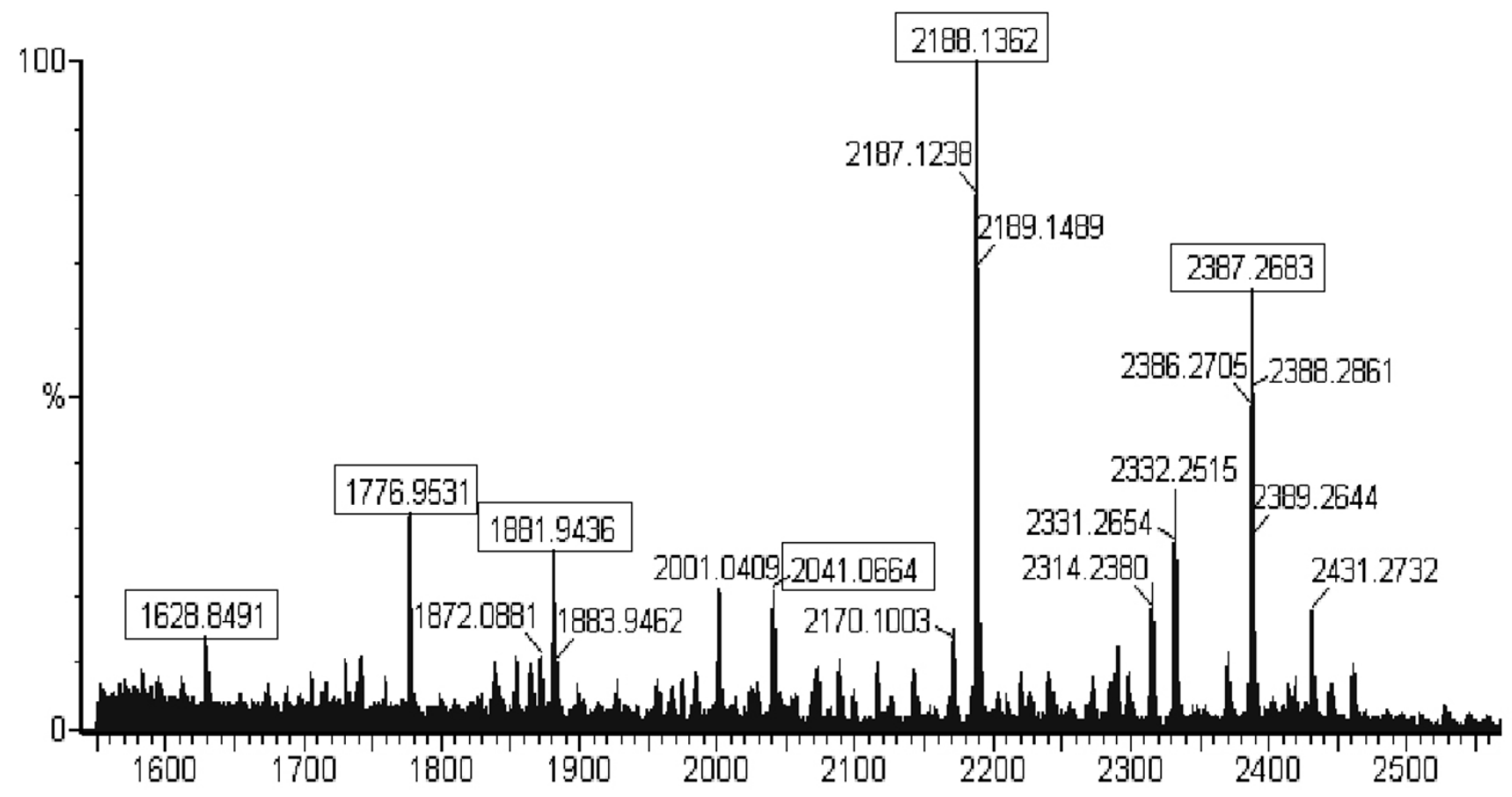

Figure 6

High-resolution mass spectrum of fractionated gastric fluid proteins on LWCX30 ProteinChip array obtained on a QTOF equipped with a PCII 000 interface. Boxed peaks were subjected to fragmentation analysis by collisioninduced dissociation MS/MS. 


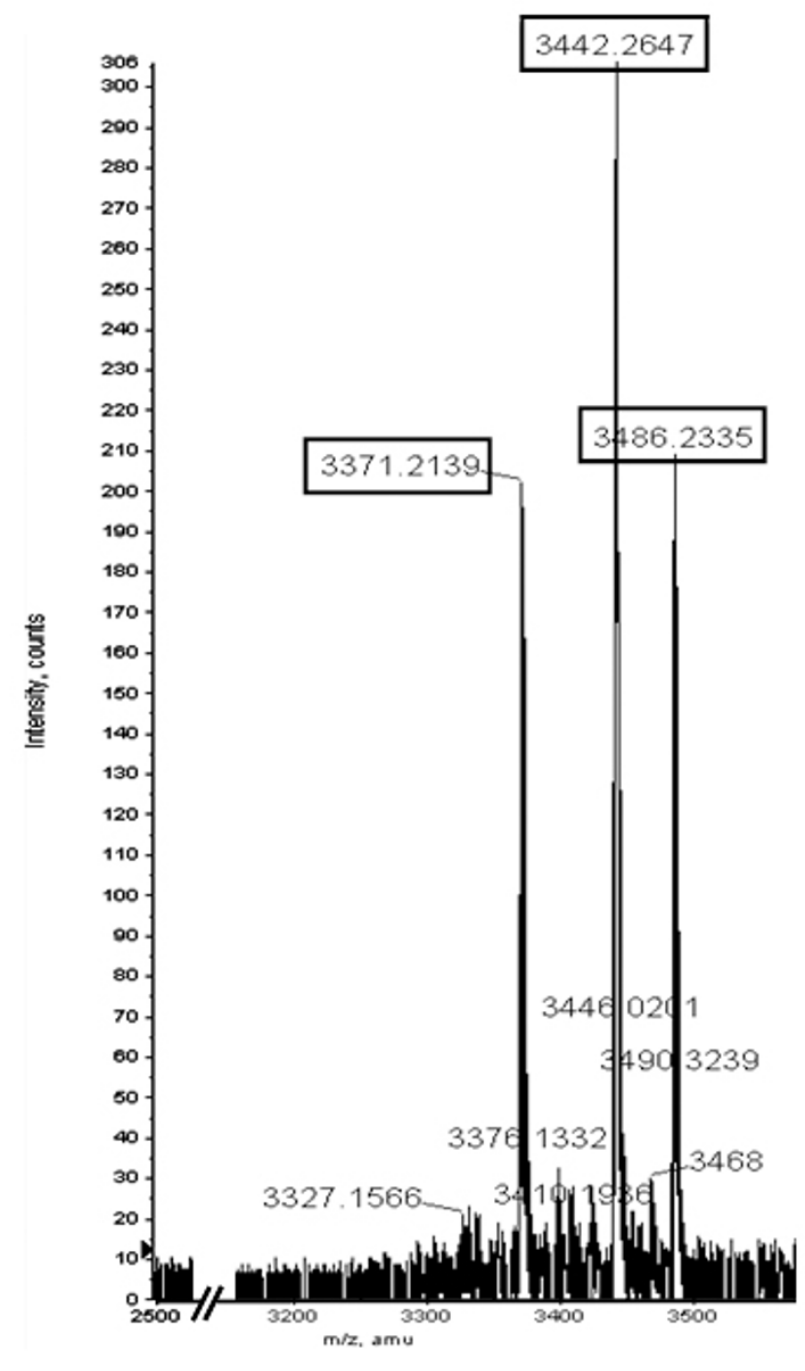

Figure 7

High-resolution mass spectrum of gastric fluid proteins on H50 ProteinChip array obtained on a QTOF equipped with a PCII000 interface. This figure shows the up-regulated triplet markers in gastric cancer. Please see Additional file 4 for the full image.

of developing intestinal-type gastric cancer [52]. However, chronic atrophic gastritis itself is not gastric cancer. A prospective 10-year longitudinal study determined that $<3 \%$ of patients with this lesion progress to gastric cancer [53], while in another prospective series, $49 \%$ of severe chronic atrophic gastritis actually regressed to less advanced lesions when followed over 5 years [54]. Hence, although serum pepsinogen levels have been intensively investigated as a cost-effective serological biopsy for non-invasive gastric cancer screening, it has low positive predictive value - $(0.77 \%-1.25 \%)$ in general population studies and $15 \%$ in selected patients [55].
We identified a prominent up-regulated marker as alphadefensin 1-3. Immunohistochemical staining of gastric adenocarcinoma tissues showed that alpha-defensin expression was restricted to infiltrating neutrophils, and was absent in normal and malignant gastric epithelial cells (data not shown). Alpha-defensin overexpression from intra-tumoral neutrophils has also been reported in oral carcinomas by peptide sequencing and immunohistochemistry [56,57]. Association of defensin expression with cancers is consistent with the role of chronic inflammation in oncogenesis. Expression of alpha-defensins 13 was higher in colorectal cancer than in normal colon $[58,59]$, and correlated with tumor invasiveness in bladder cancer [60]. Using SELDI TOF mass spectrometry, alpha-defensins 1 and 2 were among five prominent proteins in urine samples of patients with transitional cell bladder cancer [61]. Neutrophil defensin has also been identified in the proteomic signatures of ovarian and breast cancers $[62,63]$.

Our data show that protein fingerprinting of gastric fluid achieves high sensitivity and specificity because it does not rely on a single marker. Multivariate analysis of a multimarker panel of both gastric fluid and exfoliated cellular proteomes has revealed a composite pattern of up- and down-regulation of multiple components to generate a highly specific and sensitive diagnostic method for gastric cancer, including early stage disease. The protein profiles in this study were independent of age and ethnicity, and performed well in correctly identifying whether gastric fluid was obtained from a malignant or benign source (sensitivity 88\%; specificity 93\%) when tested independently against blinded samples. Combining data from training and validation sample sets, the gastric cancer proteomic signature had a positive predictive value of 0.80 . Most previous biomarker discovery studies have focused on a limited number of markers [21,23-26,38-41] and few have approached the diagnostic accuracy of this study. Relying on a single biomarker has several disadvantages. Individual markers are, in general, not very powerful in classifying disease from healthy controls. A biofluid study of bladder cancer markers using SELDI TOF mass spectrometry found that detection rates with single markers were significantly improved by biomarker combinations and clusters [61]. Our analysis confirms this experience. Thus, although the mean albumin level in gastric cancer fluid was significantly different from controls $(p=0.005)$, only 8 out of 19 cancer patients in the training set showed such elevation (data not shown), whereas transferrin and alpha1-antitrypsin levels were upregulated in an even smaller number of patients and were not significantly different from the general patient population $(p>0.1)$ (data not shown). Furthermore, many cancers share the same markers e.g. CEA, CA19-9, transferrin and alpha1-antitrypsin $[40,42,64]$. 
Defensin

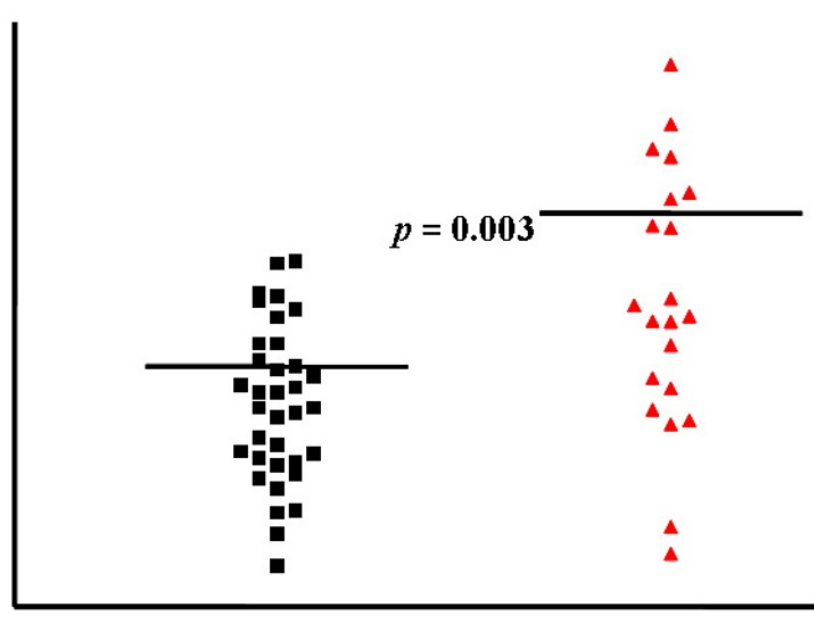

Control

Tumour
Pepsin Fragment

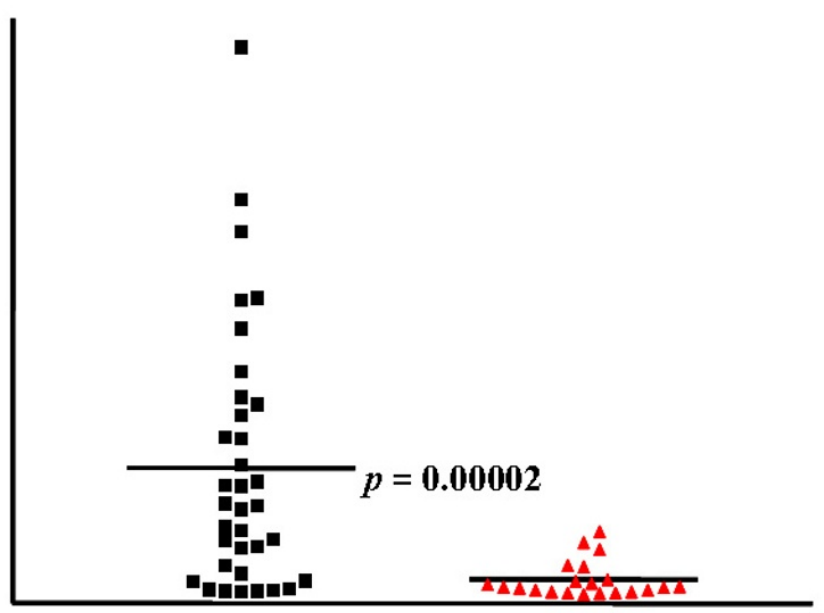

Control

Tumour

Figure 8

Scatter plots of intensity values of defensin and pepsin fragment present in gastric fluid samples of benign control and gastric cancer patients from the training set.

\section{Conclusion}

Highly informative protein profiles for biomarker discovery have been generated by high throughput analysis of both gastric fluid and exfoliated cellular proteomes using small sample volumes and simple sample processing. Identification of pepsinogens $\mathrm{A}$ and $\mathrm{C}$ among prominent down-regulated markers in gastric cancer fluid samples strengthens the biological plausibility of the proteomic signature we report for gastric cancer diagnosis. A future large cohort study is needed to confirm these results. It will be particularly important to incorporate multiple mucosal biopsies at standard sites and closely follow up patients with clinically benign gastric disorders but whose proteomic profiles are cancer-like. Given the high curative potential of early stage gastric cancer, documented false negative gastroscopic diagnosis and the expense of endoscopic surveillance of all gastric ulcers, a test that provides a pan-gastric molecular biopsy could be a clinically useful supplement to conventional gastroscopy. Proteomic signatures that distinguish benign from malignant disorders, and identify early stage cancer and pre-malignant gastric lesions with high sensitivity and specificity could make a significant contribution to reducing mortality from the second most common cause of global cancer deaths.

\section{Competing interests}

The authors declare that they have no competing interests.

\section{Authors' contributions}

OLK designed the study and wrote the manuscript; TTY analysed all samples, processed data and co-drafted the manuscript; WHC, WWK and HSO collected all samples; SYT reviewed the histopathology and performed $H$. pylori immunostaining; AKHE extracted clinical information; PH performed statistical data analysis; RV assisted in sample processing; MFH, WHN and SYK performed ELISA validation experiments; MPK reviewed historical histopathological records.

\section{Additional material}

\section{Additional file 1}

Differentially expressed 106 marker peaks in gastric cancer and benign gastric fluids (training set)

Click here for file

[http://www.biomedcentral.com/content/supplementary/17558794-1-54-S1.doc]

\section{Additional file 2}

Full image for Figure 3

Click here for file

[http://www.biomedcentral.com/content/supplementary/17558794-1-54-S2.jpeg]

\section{Additional file 3}

Differentially expressed 106 marker peaks in gastric cancer and benign gastric fluids (validation set)

Click here for file

[http://www.biomedcentral.com/content/supplementary/17558794-1-54-S3.doc] 


\author{
Additional file 4 \\ Full image for Figure 7 \\ Click here for file \\ [http://www.biomedcentral.com/content/supplementary/1755- \\ 8794-1-54-S4.jpeg]
}

\section{Acknowledgements}

We thank Cheryl Lee, Liyun Lai, Siew Hong Leong and Wai Har Ng for collecting and processing clinical samples, and Dr Luman Widjaja for providing one gastric fluid sample. The National Cancer Centre and National Medical Research Council, Singapore funded this study.

\section{References}

I. Parkin DM, Bray F, Ferlay J, Pisani P: Global cancer statistics, 2002. CA Cancer J Clin 2005, 55(2):74- 108.

2. Green PH, O'Toole KM, Slonim D, Wang T, Weg A: Increasing incidence and excellent survival of patients with early gastric cancer: experience in a United States medical center. $\mathrm{Am} J$ Med 1988, 85(5):658-66I.

3. Hundahl SA, Stemmermann GN, Oishi A: Racial factors cannot explain superior Japanese outcomes in stomach cancer. Arch Surg 1996, I31(2): 170-175.

4. Voutilainen ME, Juhola MT: Evaluation of the diagnostic accuracy of gastroscopy to detect gastric tumours: clinicopathological features and prognosis of patients with gastric cancer missed on endoscopy. Eur J Gastroenterol Hepatol 2005, I7(I 2): I 345-1349.

5. Amin A, Gilmour H, Graham L, Paterson-Brown S, Terrace J, Crofts TJ: Gastric adenocarcinoma missed at endoscopy. J R Coll Surg Edinb 2002, 47(5):68I-684.

6. Bramble MG, Suvakovic Z, Hungin AP: Detection of upper gastrointestinal cancer in patients taking antisecretory therapy prior to gastroscopy. Gut 2000, 46(4):464-467.

7. Hosokawa O, Tsuda S, Kidani E, Watanabe K, Tanigawa Y, Shirasaki $\mathrm{S}$, Hayashi $\mathrm{H}$, Hinoshita $\mathrm{T}$ : Diagnosis of gastric cancer up to three years after negative upper gastrointestinal endoscopy. Endoscopy 1998, 30(8):669-674.

8. Bytzer P: Endoscopic follow-up study of gastric ulcer to detect malignancy: is it worthwhile? Scand J Gastroenterol 1991, 26(II): II93-II99.

9. Maniatis AG, Eisen GM, Brazer SR: Endoscopic discrimination of gastric ulcers. J Clin Gastroenterol 1997, 24(4):203-206.

10. Bustamante M, Devesa F, Borghol A, Ortuno J, Ferrando MJ: Accuracy of the initial endoscopic diagnosis in the discrimination of gastric ulcers - is endoscopic follow-up study always needed? J Clin Gastroenterol 2002, 35(I):25-28.

II. Shah MA: Gastric cancer: an update. Curr Oncol Rep 2006, 8(3): $|83-| 9 \mid$.

12. Graham DY, Schwarz JT, Cain GD, Gyorkey F: Prospective evaluation of biopsy number in the diagnosis of esophageal and gastric carcinoma. Gastroenterology 1982, 82(2):228-231.

13. Karita M, Tada M: Endoscopic and histologic diagnosis of submucosal tumors of the gastrointestinal tract using combined strip biopsy and bite biopsy. Gastrointest Endosc 1994, 40(6):749-753.

14. Voutilainen ME, Juhola MT: Evaluation of the diagnostic accuracy of gastroscopy to detect gastric tumours: clinicopathological features and prognosis of patients with gastric cancer missed on endoscopy. Eur J Gastroenterol Hepatol 2005, I 7( I 2): I 345-1349.

15. Lauren P: The two histological main types of gastric carcinioma: diffuse and so-called intestinal-type carcinoma. An attempt at a histo-clinical classification. Acta Pathol Microbiol Scand 1965, 64:31-49.

16. Tusher VG, Tibshirani R, Chu G: Significance analysis of microarrays applied to the ionizing radiation response. Proc Natl Acad Sci USA 200I, 98(9):5II6-512I.

17. Yip TT, Chan JW, Cho WC, Yip TT, Wang Z, Kwan TL, Law SC, Tsang DN, Chan JK, Lee KC, Cheng WW, Ma VW, Yip C, Lim CK,
Ngan RK, Au JS, Chan A, Lim WW, Ciphergen SARS Proteomics Study Group: Protein chip array profiling analysis in patients with severe acute respiratory syndrome identified serum amyloid A protein as a biomarker potentially useful in monitoring the extent of pneumonia. Clin Chem 2005, 5 I (I):47-55.

18. Semmes OJ, Feng Z, Adam BL, Banez LL, Bigbee WL, Campos D, Cazares LH, Chan DW, Grizzle WE, Izbicka E, Kagan J, Malik G, McLerran D, Moul JW, Partin A, Prasanna P, Rosenzweig J, Sokoll LJ, Srivastava S, Srivastava S, Thompson I, Welsh MJ, White N, Winget $M$, Yasui $Y$, Zhang Z, Zhu L: Evaluation of serum protein profiling by surface-enhanced laser desorption/ionization time-offlight mass spectrometry for the detection of prostate cancer: I. Assessment of platform reproducibility. Clin Chem 2005, $51(1): 102-112$.

19. Kim YH, Kim NG, Lim JG, Park C, Kim H: Chromosomal alterations in paired gastric adenomas and carcinomas. Am J Pathol 200I, I 58(2):655-662.

20. El-Zimaity HMT, Graham DY: Evaluation of gastric mucosal biopsy site and number for identification of Helicobacter pylori or intestinal metaplasia: role of the Sydney system. Hum Pathol 1999, 30(1):72-77.

21. Dragutinovic VV, Radovanovic NS, Izrael-Zivkovic LT, Vrvic MM: Detection of gelatinase $B$ activity in serum of gastric cancer patients. World J Gastroenterol 2006, I 2(I): 105-109.

22. Macri A, Versaci A, Loddo S, Scuderi G, Travagliante M, Trimarchi G, Teti D, Famulari C: Serum levels of interleukin Ibeta, interleukin 8 and tumour necrosis factor alpha as markers of gastric cancer. Biomarkers 2006, I I (2): I84-I93.

23. Ren J, Chen Z, Juan SJ, Yong XY, Pan BR, Fan DM: Detection of circulating gastric carcinoma-associated antigen $\mathrm{MG7-Ag}$ in human sera using an established single determinant immuno-polymerase chain reaction technique. Cancer 2000, 88(2):280-285.

24. He XX, Yang J, Ding YW, Liu W, Shen OY, Xia HH: Increased epithelial and serum expression of macrophage migration inhibitory factor (MIF) in gastric cancer: potential role of MIF in gastric carcinogenesis. Gut 2006, 55(6):797-802.

25. Lin Y, Kikuchi S, Obata Y, Yagyu K, Tokyo Research Group on Prevention of Gastric Cancer: Serum levels of transforming growth factor betal are significantly correlated with venous invasion in patients with gastric cancer. J Gastroenterol Hepatol 2006, $21(2): 432-437$.

26. Ebert MP, Lamer S, Meuer J, Malferthenier P, Reymond M, Buschmann $T$, Rocken $C$, Seibert $V$ : Identification of the thrombin light chain a as the single best mass for differentiation of gastric cancer patients from individuals with dyspepsia by proteome analysis. J Proteome Res 2005, 4(2):586-590.

27. Qian HG, Shen J, Ma H, Ma HC, Su YH, Hao CY, Xing BC, Huang XF, Shou CC: Preliminary study on proteomics of gastric carcinoma and its clinical significance. World J Gastroenterol 2005, I I (40):6249-6253.

28. Poon TC, Sung JJ, Chow SM, Ng EK, Yu AC, Chu ES, Hui AM, Leung WK: Diagnosis of gastric cancer by serum proteomic fingerprinting. Gastroenterology 2006, I 30(6): | 1858- I864.

29. Ebert MP, Meuer J, Wiemer JC, Schulz HU, Reymond MA, Traugott $\mathrm{U}$, Malfertheiner P, Rocken C: Identification of gastric cancer patients by serum protein profiling. J Proteome Res 2004, 3(6): $126 \mid-1266$.

30. He QY, Cheung YH, Leung SY, Yuen ST, Chu KM, Chiu JF: Diverse proteomic alterations in gastric adenocarcinoma. Proteomics 2004, 4(I0):3276-3287.

31. Kielan W, Suzanowicz J, SiewiNski M, Saleh Y, Janocha A, Skalski A, Tarnawa R: Evaluation of changes in the activity of proteolytic enzymes and their inhibitors in the processes that accompany the growth of gastric cancer. Gastric Cancer 2004, 7(I): $17-23$.

32. Ebert MP, Kruger S, Fogeron ML, Lamer S, Chen J, Pross M, Schulz HU, Lage H, Heim S, Roessner A, Malfertheiner P, Rocken C: Overexpression of cathepsin $B$ in gastric cancer identified by proteome analysis. Proteomics 2005, 5(6): 1693-1704.

33. Qiao SX, Yuan M, Liu YL, Lin XS, Zhang XP, Tobi M: Detection of gastric cancer and premalignant lesions by novel marker glycoprotein 87 using monoclonal antibody Adnab-9. Cancer Epidemiol Biomarkers Prev 2003, I 2(10): 1095- 1099.

34. Cunningham SC, Kamangar F, Kim MP, Hammoud S, Haque R, lacobuzio-Donahue CA, Maitra A, Ashfaq R, Hustinx S, Heitmiller RE, 
Choti MA, Lillemoe KD, Cameron JL, Yeo C], Schulick RD, Montgomery E: Claudin-4, mitogen-activated protein kinase kinase $\mathbf{4}$, and stratifin are markers of gastric adenocarcinoma precursor lesions. Cancer Epidemiol Biomarkers Prev 2006, I 5(2):28I-287.

35. Ryu JW, Kim H], Lee YS, Myong NH, Hwang CH, Lee GS, Yom HC: The proteomics approach to find biomarkers in gastric cancer. J Korean Med Sci 2003, 18(4):505-509.

36. Wang KJ, Wang RT, Zhang JZ: Identification of tumor markers using two-dimensional electrophoresis in gastric carcinoma. World J Gastroenterol 2004, 10(15):2179-2183.

37. Jang JS, Cho HY, Lee YJ, Ha WS, Kim HW: The differential proteome profile of stomach cancer: identification of the biomarker candidates. Oncol Res 2004, I 4( I 0):49|-499.

38. Guadagni F, Roselli M, Amato T, Cosimelli M, Perri P, Casale V, Carlini M, Santoro E, Cavaliere R, Greiner JW, Schlom J: CA 72-4 measurement of tumor-associated glycoprotein 72 (TAG-72) as a serum marker in the management of gastric carcinoma. Cancer Res 1992, 52(5): 1222-1227.

39. Ishigami S, Natsugoe S, Hokita S, Che X, Tokuda K, Nakajo A Iwashige $H$, Tokushige M, Watanabe T, Takao S, Aikou T: Clinical importance of preoperative carcinoembryonic antigen and carbohydrate antigen 19-9 levels in gastric cancer. J Clin Gastroenterol 200I, 32(I):4I-44.

40. Carpelan-Holmstrom M, Louhimo J, Stenman UH, Alfthan $\mathrm{H}$, Haglund C: CEA, CA 19-9 and CA 72-4 improve the diagnostic accuracy in gastrointestinal cancers. Anticancer Res 2002, 22(4):23||-23|6.

4I. Marrelli D, Pinto E, De Stefano A, Faarnetani M, Garosi L, Roviello F: Clinical utility of CEA, CA 19-9 and CA 72-4 in the follow-up of patients with resectable gastric cancer. Am J Surg $200 \mathrm{I}$ $181(1): 16-19$

42. Takahashi Y, Takeuchi T, Sakamoto J, Touge T, Mai M, Ohkura H, Kodaira S, Okajima K, Nakazato H, Tumor Marker Committee: The usefulness of CEA and/or CAI 9-9 in monitoring for recurrence in gastric cancer patients: a prospective clinical study. Gastric Cancer 2003, 6(3): 142-I 45.

43. Micali B, Florio MG, Venuti A, Artemisia A, Caputo G, Brancato U: Usefulness of carcinoembryonic antigen measurement in gastric juice of patients with gastric disorders. J Clin Gastroenterol I983, 5(5):4II-4I5.

44. Harrison JD, Stanley J, Morris DL: CEA and CA $19-9$ in gastric juice and serum: an aid in the diagnosis of gastric carcinoma? Eur J Surg Oncol 1989, 15(3):253-257.

45. Duraker N, Naci Celik A, Gencler N: The prognostic significance of gastric juice CA 19-9 and CEA levels in gastric carcinoma patients. Eur J Surg Oncol 2002, 28(8):844-849.

46. Tocchi A, Costa G, Lepre L, Liotta G, Mazzoni G, Cianetti A, Vannin $P:$ The role of serum and gastric juice levels of carcinoembryonic antigen, CA $19-9$ and CA 72-4 in patients with gastric cancer. J Cancer Res Clin Oncol 1998, I 24(8):450-455.

47. Lee K, Kye M, Jang JS, Lee OJ, Kim T, Lim D: Proteomic analysis revealed a strong association of a high level of alpha I-antitrypsin in gastric juice with gastric cancer. Proteomics 2004, 4(II):3343-3352.

48. Hsu PI, Chen $\mathrm{CH}$, Hsieh CS, Chang WC, Lai KH, Lo GH, Hsu PN, Tsay FW, Chen YS, Hsiao M, Chen HC, Lu PJ: $\alpha$ I-Antitrypsin precursor in gastric juice is a novel biomarker for gastric cancer and ulcer. Clin Cancer Res 2007, I3(3):876-883.

49. Ludwig JA, Weinstein JN: Biomarkers in cancer staging, prognosis and treatment selection. Nat Rev Cancer 2005, 5(I I):845-856.

50. Rifai N, Gillette MA, Carr SA: Protein biomarker discovery and validation: the long and uncertain path to clinical utility. Nat Biotechnol 2006, 24(8):97।-983.

5I. Melle C, Ernst G, Schimmel B, Bleul A, Kaufmann R, Hommann M, Richter KK, Daffner W, Settmacher U, Claussen U, von Eggeling F: Characterization of pepsinogen $\mathbf{C}$ as a potential biomarker for gastric cancer using a histo-proteomic approach. J Proteome Res 2005, 4(5): I799-1804.

52. Faraji El, Frank BB: Multifocal atrophic gastritis and gastric carcinoma. Gastroenterol Clin North Am 2002, 3 I (2):499-516.

53. Inoue M, Tajima K, Matsuura A, Suzuki T, Nakamura T, Ohashi K, Nakamura S, Tominaga S: Severity of chronic atrophic gastritis and subsequent gastric cancer occurrence: a 10 -year prospective cohort study in Japan. Cancer Lett 2000, I6I(I):105-112.
54. You WC, Li JY, Blot WJ, Chang YS, Jin ML, Gail MH, Zhang L, Liu WD, Ma JL, Hu YR, Mark SD, Correa P, Fraumeni JF, Xu GW: Evolution of precancerous lesions in a rural Chinese population at high risk of gastric cancer. Int / Cancer 1999, 83(5):615-6I9.

55. Dinis-Ribeiro M, Yamaki G, Miki K, Costa-Pereira A, Matsukawa M, Kurihara M: Meta-analysis on the validity of pepsinogen test for gastric carcinoma, dysplasia or chronic atrophic gastritis screening. J Med Screen 2004, I I (3): | 14|-I47.

56. Mizukawa N, Sawaki K, Nagatsuka H, Kamio M, Yamachika E, Fukunaga J, Ueno T, Takagi S, Sugahara T: Human alpha-and betadefensin immunoreactivity in oral mucoepidermoid carcinomas. Anticancer Res 200I, 2I(3C):2I7I-2I74.

57. Lundy FT, Orr DF, Gallagher JR, Maxwell P, Shaw C, Napier SS, Gerald Cowan C, Lamey PJ, Marley JJ: Identification and overexpression of human neutrophil $\alpha$-defensins (human neutrophil peptides I, 2 and 3 ) in squamous cell carcinomas of the human tongue. Oral Oncol 2004, 40(2): I39-144.

58. Melle C, Ernst G, Schimmel B, Bleul A, Thieme H, Kaufmann R, Mothes H, Settmacher U, Claussen U, Halbhuber KJ, Von Eggeling F: Discovery and identification of alpha-defensins as low abundant, tumor-derived serum markers in colorectal cancer. Gastroenterology 2005, I 29(I):66-73.

59. Albrethsen J, Bogebo R, Gammeltoft S, Olsen J, Winther B, Raskov H: Upregulated expression of human neutrophil peptides I, 2 and 3 (HNP I-3) in colon cancer serum and tumours: a biomarker study. BMC Cancer 2005, 1 9:5-8.

60. Holterman DA, Diaz JI, Blackmore PF, Davis JW, Schellhammer PF, Corica A, Semmes OJ, Vlahou A: Overexpression of alphadefensin is associated with bladder cancer invasiveness. Urol Oncol 2006, 24(2):97-108.

6I. Vlahou A, Schellhammer PF, Mendrinos S, Patel K, Kondylis FI, Gong L, Nasim S, Wright GL: Development of a novel proteomic approach for the detection of transitional cell carcinoma of the bladder in urine. Am J Pathol 200I, I58(4): I49|-I502.

62. Zhang Z, Bast RC Jr, Yu Y, Li J, Sokoll LJ, Rai AJ, Rosenzweig JM, Cameron B, Wang YY, Meng XY, Berchuck A, Van Haaften-Day C, Hacker NF, de Bruijn HW, Zee AG vander, Jacobs IJ, Fung ET, Chan DW: Three biomarkers identified from serum proteomic analysis for the detection of early stage ovarian cancer. Cancer Res 2004, 64( I 6):5882-5890.

63. Celis JE, Gromov P, Cabezon T, Moreira JM, Ambartsumian N, Sandelin K, rank F, Gromova I: Proteomic characterization of the interstitial fluid perfusing the breast tumor microenvironment. Mol Cell Proteomics 2004, 3(4):327-344.

64. Satoh J, Darley-Usmar VM, Kashimura H, Fukutomi H, Anan K, Ohsuga T: Analysis of pure pancreatic juice proteins by twodimensional gel electrophoresis in cases of pancreatic cancer. Gastroenterol Jpn 1986, 2 I(6):623-629.

\section{Pre-publication history}

The pre-publication history for this paper can be accessed here:

http://www.biomedcentral.com/1755-8794/1/54/prepub

Publish with Bio Med Central and every scientist can read your work free of charge

"BioMed Central will be the most significant development for disseminating the results of biomedical research in our lifetime. "

Sir Paul Nurse, Cancer Research UK

Your research papers will be:

- available free of charge to the entire biomedical community

- peer reviewed and published immediately upon acceptance

- cited in PubMed and archived on PubMed Central

- yours - you keep the copyright 